\title{
Acquired purpura fulminans
}

INSERM

\section{Source}

INSERM. (1999). Orphanet: an online rare disease and orphan drug data base. Acquired purpura fulminans. ORPHA:49566

Purpura fulminans (PF) is a life-threatening, rapidly progressive thrombotic disorder affecting mainly neonates and children that is characterized by purpuric skin lesions and disseminated intravascular coagulation. PF may prog ress rapidly to multi-organ failure caused by thrombotic occlusion of small and medium-sized blood vessels. There are two forms of PF that are classified according to triggering mechanisms: acute infectious (the most common form), and idiopathic PF. 